\title{
Badan Penyelenggara Jaminan Sosial (BPJS) Kesehatan Sebagai Pelayanan Publik
}

\author{
Solechan \\ Fakultas Hukum, Universitas Diponegoro \\ solechan@live.undip.ac.id
}

\begin{abstract}
Abstrack
The purpose of this research is to find out how the role of the health insurance provider (BPJS) as a form of public service in Indonesia. Research is a normative study with a comparative approach. The research results show that public services or public services can be defined as all forms of services, both in the form of goods and services which in principle are the responsibility and are carried out by government agencies at the central, regional, and in the environment of state-owned enterprises or business entities Regional Owned. One of them is the Social Security Organizing Agency is a legal entity to organize social security programs to ensure all people can meet the basic needs of a decent life. BPJS is held based on the principles of humanity, benefits, and social justice for all Indonesian people with the aim of realizing the fulfillment of the basic needs of a decent life for every Indonesian people who have become basic human rights.
\end{abstract}

Keywords: Social Security Organizing Agency, Health, Public Services

\begin{abstract}
Abstrack
Penelitian ini bertujuan utnuk mengetahui bagaimanakah peran badan penyelenggara jaminan sosial (BPJS) kesehatan sebagai salah satu bentuk pelayanan publik di Indonesia. Penelitian merupakan penelitian normatif dengan pendekatan perbandingan. Hasil penelitian menujukan bahwa Pelayanan publik atau pelayanan umum dapat didefinisikan sebagai segala bentuk jasa pelayanan, baik dalam bentuk barang maupun jasa yang pada prinsipnya menjadi tanggung jawab dan dilaksanakan oleh Instansi Pemerintah di Pusat, di Daerah, dan di lingkungan Badan Usaha Milik Negara atau Badan Usaha Milik Daerah. Salah satunya adalah Badan Penyelenggara Jaminan Sosial merupakan sebuah badan hukum untuk menyelenggarakan program jaminan sosial untuk menjamin seluruh rakyat agar dapat memenuhi kebutuhan dasar hidup yang layak. BPJS diselenggarakan berdasarkan asas kemanusiaan, manfaat, dan keadilan sosial bagi seluruh rakyat Indonesia dengan tujuan untuk mewujudkan pemenuhan kebutuhan dasar hidup yang layak bagi setiap rakyat Indonesia yang sudah menjadi hak dasar manusia.
\end{abstract}

Kata Kunci: Badan Penyelenggara Jaminan Sosial, Kesehatan, Pelayanan Publik

\section{A. Pendahuluan}

Pembukaan Undang-Undang Dasar Negara Republik Indonesia Tahun 1945 yang telah disepakati menjadi landasan ideologi bangsa memiliki cita-cita luhur yaitu melindugi 
segenap bangsa Indonesia dan seluruh tumpah darah Indonesia dan untuk memajukan kesejahteraan umum, mencerdaskan kehidupan bangsa dan ikut melaksanakan ketertiban dunia yang berdasarkan kemerdekaan, perdamaian abadi, dan keadilan sosial. Salah satu bentuk konkret dari kesejahteraan umum yang tertuang dalam cita-cita bangsa Indonesia adalah kesehatan yang harus diwujudkan dalam berbagai upaya agar dapat dirasakan kemanfaatan dan keadilannya oleh seluruh rakyat Indonesia.

Selain dalam pembukaan UUD NRI Tahun 1945, kesehatan juga merupakan salah satu hak asasi manusia yang diakui dan tertuang dalam Pasal $28 \mathrm{H}$ ayat (1) Undang-Undang Dasar Negara Republik Indonesia Tahun 1945 yang menyatakan bahwa setiap orang berhak memperoleh pelayanan kesehatan. Dalam pelaksanaannya Negara juga dituntut untuk dapat melaksanakan kewajibannya sebagaimana tertuang dalam Pasal 34 ayat (3) Undang-Undang Dasar Negara Republik Indonesia Tahun 1945 untuk bertanggung jawab atas penyediaan fasilitas pelayanan kesehatan dan fasilitas pelayanan umum yang layak.

Dalam menjalankan tugasnya, pemerintah memiliki 4 (empat) fungsi utama yang harus dijalankan, yaitu: (1) fungsi pelayanan masyarakat (public sevice function), (2) fungsi pembangunan (development function), (3) fungsi pemberdayaan (protection function), dan (4) fungsi pengaturan (Putri \& Murdi, 2019). Dari keempat fungsi tersebut, memang tidak memiliki tingkatan yang berarti harus dilaksanakan semuanya oleh pemerintah, namun fungsi pelayanan masyarakat (public sercie function) dinilai sangat strategis karena dapat menentukan peran pemerintah dalam memberikan pelayanan yang sebaik-baiknya bagi masyarakat yang merupakan bentuk daripada pelayanan publik.

Masalah kesehatan di Indonesia yang tidak kunjung usai membuat pemerintah harus mengambil tindakan supaya masyarakat tetap dapat merasakan keadilan dan memperoleh haknya serta tidak menimbulkan kerugian. Guna meningkatkan kualitas kesehatan masyarakat pemerintah mengadakan jaminan sosial. Jaminan sosial ini diselenggarakan oleh pemerintah yang berguna untuk memenuhi kebutuhan hidup dasar yang layak, dimulai dari Jamkesmas, Jamkesda, AKSES dan yang terbaru adalah Badan Pelenggara Jaminan Sosial (BPJS) Kesehatan (M. Pertiwi \& Nurcahyanto, 2017) yang merupakan Badan Usaha Milik Negara (BUMN) kemudian berubah menjadi Badan Hukum Publik yang bertugas untuk menyelenggarakan jaminan kesehatan bagi seluruh rakyat Indonesia.

Oleh sebab itu maka perlu dipahami bahwa prinsip good governance menjadi landasan negara dalam menerapkan pelayanan kesehatan (Hasan, Ayuningtyas, \& Misnaniarti, 2016) yang berarti memperhatikan pelayanan kesehatan masyarakatnya serta memberi 
perlindungan hukum dan kepastian hukum dalam penyelenggaraannya. Walaupun sudah termaktub demikian, namun Indonesia masih banyak memiliki pekerjaan rumah yang harus diselesaikan dalam pelayanan kesehatan, disamping keterbatasan yang dimiliki oleh pemerintah, mereka juga harus tetap selalu mengevaluasi agar kedepannya pelayanan kesehatan melalui BPJS Kesehatan yang diberikan dari pemerintah kepada masyarakat dapat dilaksanakan dan dirasakan keadilannya bagi seluruh rakyat Indonesia (Batubara, 2006). Berdasarkan maka makalah singkat ini akan menjelas kan tentang Apa yang dimaksud dengan Pelayanan Publik? ; Apa yang dimaksud dengan Badan Penyelenggara Jaminan Sosial (BPJS) Kesehatan? Dan Bagaimana cara meningkatkan mutu pelayanan publik?

\section{B. Pembahasan}

\section{a. Pelayanan Publik}

Pelayanan publik adalah serangkaian kegiatan guna pemenuhan kebutuhan pelayanan setiap warga negara atas barang, jasa, dan/atau pelayanan administratif yang disediakan oleh penyelenggara pelayanan publik (Publik \& Indonesia, 2009). Pelayanan publik yang dilaksanakan berasaskan kepentingan umum, kepastian hukum, kesamaan hak, keseimbangan hak dan kewajiban, dan lainnya. Dalam pelaksanaan pelayanan publik, peran serta masyarakat sangatlah dibutuhkan dalam bentuk kerja sama, pemenuhan hak dan kewajiban serta berperan aktif dalam penyusunan kebijakan pelayanan publik. Masyarakat juga dapat membentuk sebuah lembaga pengawas pelayanan publik dengan tata cara yang telah diatur dalam peraturan pemerintah.

Dalam pelaksanaannya masyarakat yang merasa dirugikan oleh pelaksanaan pelayanan publik dapat menggugat penyelenggara pelayanan publik melalui peradilan tata usaha negara (dalam hal terjadi perbuatan melawan hukum).

Berdasarkan Undang-Undang Nomor 25 Tahun 2009 tentang Pelayanan Publik, ruang lingkup pelayanan publik terbagi atas dua bagian, yaitu: 1). Pelayanan Barang dan Jasa Publik: Pelayanan pengadaan dan penyaluran barang dan jasa publik bisa dikatakan mendominasi seluruh pelayanan yang disediakan pemerintah kepada masyarakat (Muradi \& Rusli, 2013). Pelayanan publik kategori ini bisa dilakukan oleh instansi pemerintah yang sebagian atau seluruh dananya merupakan kekayaan negara yang tidak bisa dipisahkan atau bisa diselenggarakan oleh badan usaha milik pemerintah yang sebagian atau seluruh dananya berasal dari kekayaan negara yang dipisahkan (Badan Usaha Milik Negara/BUMN). 2). Pelayanan Administratif: Pelayanan publik dalam kategori ini meliputi tindakan administratif 
pemerintah yang diwajibkan oleh negara dan diatur dalam perundang-undangan dalam rangka mewujudkan perlindungan pribadi, keluarga, kehormatan, dan harta benda juga kegiatan administratif yang dilakukan oleh instansi non-pemerintah yang diwajibkan oleh negara dan diatur dalam perundang-undangan serta diterapkan berdasarkan perjanjian dengan penerima pelayanan (Hayat (Universitas Islam Malang), 2014).

Di Indonesia pelayanan publik sebenarnya sudah berjalan selama bertahun-tahun lamanya namun tetap kebutuhan akan perbaikan pelayanan publik semakin dirasakan arti pentingnya (Sirajuddin, 2016). Hal ini disebabkan karena dinilai sangat penting dalam pelayanan publik memperhatikan kesehatan yang merupakan hak asasi manusia yang harus dijunjung tinggi serta dijamin oleh Undang-Undang Dasar Negara Republik Indonesia Tahun 1945 dan peraturan perundang-undangan lainnya supaya dapat meningkatkan derajat kesehatan masyarakat Indonesia setinggi-tingginya.

(Muhaimin, 2018) Partisipasi masyarakat pada dasarnya merupakan suatu bentuk keterliatan dan keikut sertaan masyarakat secara aktif dalam keseluruhan proses kegiatan. Partisipasi masyarakat adalah kerja sama antara masyarakat dengan pemerintah. Peran serta masyarakat tidak terbatas dalam pengertian ikut serta secara fisik tetapi keterlibatan yang memungkinkan mereka melaksanakan penilaian terhadap masalah dan potensi yang terdapat dalam lingkungan sendiri. Kemudian menentukan kegiatan yang mereka butuhkan.

Pelayanan publik yang berkualitas sudah seharusnya menjadi hak setiap warga negara, dimana warga negara juga berhak mendapatkan perlindungan akan hak-haknya, didengar suaranya, sekaligus dihargai nilai dan preferensinya. Luasnya pelayanan publik dengan kompleksitas permasalahannya membutuhkan partisipasi semua elemen masyarakat untuk mewujudkan perbaikan. Masyarakat harus turun tangan secara aktif dan menuntut pelayanan publik berkualitas yang merupakan haknya (Hardiansyah, 2011) dimana masyarakat memang berhak mendapatkan pelayanan publik sebagaimana dituangkan dalam Pembukaan UndangUndang Dasar Negara Republik Indonesia tahun 1945 (Larasati, 2010). Dengan demikian, mereka dapat memiliki kekuasaan untuk menilai, menolak dan menuntut secara politis untuk bertanggung jawab atas penyediaan pelayanan publik yang mereka terima. Konsep ini merupakan The New Public Service yang dikembangkan oleh Janet V. Denhardt dan Robert B. Denhardt pada tahun 2003 (Kurniawan, 2017).

Tuntutan masyarakat terhadap peningkatan kualitas pelayanan publik terus berkembang seiring dengan meningkatnya kesadaran warga negara memiliki hak untuk dilayani, sedangkan kewajiban pemerintah adalah melayani masyarakat (Pratama, 2015). Periwtiwa 
tersebut merupakan dampak keterpinggiran rakyat atas hak-haknya yang belum sesuai dengan Standar Pelayanan Minimal (SPM) oleh pemerintah dalam urusan-urusan publik (Kamarni, 2011).

Dalam penyelenggaraan pelayanan publik, pemerintah dalam Undang-Undang tentang Pelayanan Publik Nomor 25 Tahun 2009 dan Keputusan Menteri Pendayagunaan Aparatur negara Nomor 63/KEP/M.PAN/7/2003 telah merumuskan apa yang menjadi asas, prinsip, dan standar pelayanan publik, hal ini bertujuan untuk meningkatkan kualitas pelayanan publik (Rezha, Rochmah, \& Siswidiyanto, 2009).

\section{Badan Penyelenggara Jaminan Sosial (BPJS) Kesehatan}

Badan Penyelenggara Jaminan Sosial merupakan sebuah badan hukum untuk menyelenggarakan program jaminan sosial untuk menjamin seluruh rakyat agar dapat memenuhi kebutuhan dasar hidup yang layak (Pemerintah Republik Indonesia, 2011). BPJS diselenggarakan berdasarkan asas kemanusiaan, manfaat, dan keadilan sosial bagi seluruh rakyat Indonesia dengan tujuan untuk mewujudkan pemenuhan kebutuhan dasar hidup yang layak bagi setiap rakyat Indonesia yang sudah menjadi hak dasar manusia.

Pada awalnya lembaga jaminan sosial yang ada di Indonesia adalah lembaga asuransi jaminan kesehatan PT Askes Indonesia yang kemudian menjadi BPJS Kesehatan. Pada awal 2013, PT Askes Menjadi BPJS Kesehatan. BPJS diharapkan mampu memberikan pelayanan kesehatan kepada masyarakat lebih baik lagi dari sebelumnya (Janis, 2014).

Namun dalam praktiknya sebenarnya masih banyak ditemukan persoalan dalam pelaksanaan BPJS dengan adanya perbedaan signifikan kualitas pelayanan berdasarkan keselamatan pasien, efektivitas dan efisiensi, dan berorientasi pada pasien, serta kepuasan pasien antara pasien yang menggunakan BPJS dan umum (tidak menggunakan BPJS) (A. Pertiwi, 2017). Dari perbedaan tersebut diketahui hingga sampai saat ini masih terdapat kekurangan yang harus dievaluasi dan diperharui oleh pemerintah guna meningkatkan mutu pelayanan kesehatan. BPJS memiliki visi dan misi di dalamnya yang harus dilaksanakan, antara lain: Visi BPJS Kesehatan : “Cakupan Semesta 2019”. paling lambat 1 Januari 2019, seluruh penduduk Indonesia memiliki jaminan kesehatan nasional untuk memperoleh manfaat pemeliharaan kesehatan dan perlindungan dalam memenuhi kebutuhan dasar kesehatannya yang diselenggarakan oleh BPJS Kesehatan yang handal, unggul dan terpercaya.

Misi BPJS Kesehatan : Membangun kemitraan strategis dengan berbagai lembaga dan mendorong partisipasi masyarakat dalam perluasan kepesertaan Jaminan Kesehatan Nasional (JKN); Menjalankan dan mamantapkan sistem jaminan pelayanan kesehatan yang efektif, 
efisien dan bermutu kepada peserta melalui kemitraan yang optimal dengan fasilitas kesehatan; Mengoptimalkan pengelolaan dana program jaminan sosial dan dana BPJS Kesehatan secara efektif, efisien, transparan dan akuntabel untuk mendukung kesinambungan program; Membangun BPJS Kesehatan yang efektif berlandaskan prinsip-prinsip tata kelola organisasi yang baik dan meningkatkan kompetensi pegawai untuk mencapai kinerja unggul; Mengimplementasikan dan mengembangkan sistem perencanaan dan evaluasi, kajian, manajemen mutu dan manajemen resiko atas seluruh operasionalisasi BPJS Kesehatan; Mengembangkan dan memantapkan teknologi informasi dan komunikasi untuk mendukung operasionalisasi BPJS Kesehatan

Dalam Undang-Undang BPJS telah ditentukan bahwa BPJS Kesehatan memiliki fungsi untuk menyelenggarakan program jaminan kesehatan. Jaminan Kesehatan menurut UU SJSN diselenggarakan secara nasional berdasarkan prinsip asuransi sosial dan prinsip ekuitas, dengan tujuan menjamin agar peserta memperoleh manfaat pemeliharaan kesehatan dan perlindungan dalam memenuhi kebutuhan dasar kesehatan.

Dalam implementasi pelayanan kesehatan, BPJS juga memperhatikan hak para pekerja dengan menghadirkan BPJS Ketenagakerjaan. BPJS Ketenagakerjaan menurut UU BPJS berfungsi menyelenggarakan 4 program, yaitu program jaminan kecelakaan kerja, jaminan hari tua, jaminan pensiun, dan jaminan kematian.

Menurut UU SJSN program jaminan kecelakaan kerja diselenggarakan secara nasional berdasarkan prinsip asuransi sosial, dengan tujuan menjamin agar peserta memperoleh manfaat pelayanan kesehatan dan santunan uang tunai apabila seorang pekerja mengalami kecelakaan kerja atay menderita penyakit akibat kerja. Selanjutnya program jaminan hari tua diselenggarakan secara nasional berdasarkan prinsip asuransi sosial atau tabungan wajib, dengan tujuan untuk menjamin agar peserta menerima uang tunai apabila memasuki masa pensiun, mengalami cacat total tetap, atau meninggal dunia.

Kemudian program jaminan pensiun diselenggarakan secara nasional berdasarkan prinsip asuransi sosial atau tabungan wajib, untuk mempertahankan derajat kehidupan yang layak pada saat peserta kehilangan atau berkurang penghasilannya karena memasuki usia pensiun atau mengalami cacat total tetap. Jaminan pensiun ini diselenggarakan berdasarkan manfaat pasti. Sedangkan program jaminan kematian diselenggarakan secara nasional berdasarkan prinsip asuransi sosial dengan tujuan untuk memberikan santunan kematian yang dibayarkan kepada ahli waris peserta yang meninggal dunia (BPJS Ketenagakerjaan, 2016). 


\section{Cara Meningkatkan Mutu Pelayanan Publik}

Penerapan standar dan partisipasi masyarakat dalam penyelenggaraan pelayanan publik tersebut sudah pasti harus didukung dengan strategi yang selaras dengan sasaran dan indikator keberhasilan yang ditetapkan. Pada Grand Design Reformasi Birokrasi Tahun 2010 - 2025 ditetapkan indikator keberhasilan program berupa peningkatan integritas pelayanan publik di Pusat dan Daerah, serta peringkat kemudahan berusaha. Dengan demikian strategi sebaiknya difokuskan pada dua hal yaitu penyempurnaan sistem pelayanan dan Peningkatan kinerja layanan.

Rencana aksi Penyempurnaan Pelayanan Publik antara lain dapat berupa perbaikan terhadap mekanisme dan akses pelayanan dibidang perikanan tangkap/budidaya/pengolahan, perkarantinaan ikan, pengawasan sumber daya kelautan dan perikanan serta pendidikan perikanan. Indikator keberhasilannya adalah masyarakat/pelaku usaha perikanan lebih mudah mengurus perijinan tanpa dibebani aturan tambahan, sehingga menarik dan kompetitif bagi calon investor (Mahsyar, 2011).

Rencana aksi peningkatan kinerja layanan antara lain dapat berupa penerapan reward and punishment dalam pelayanan. Indikator keberhasilannya (outcome), terwujudnya pelayanan prima tanpa pungli diberbagai bidang usaha perikanan tangkap/budidaya/pengolahan, perkarantinaan ikan, pengawasan sumber daya kelautan dan perikanan dan pendidikan perikanan. Disamping itu strategi yang tidak boleh dilupakan adalah sinergitas lintas instansi agar upaya-upaya peningkatan kualitas pelayanan efisien dan efektif.

Dengan kata lain keberhasilan penyelenggaraan pelayanan publik ditentukan oleh tingkat kepuasan penerima layanan (masyarakat). Kepuasan masyarakat dicapai apabila masyarakat memperoleh pelayanan sesuai dengan yang dibutuhkan dan diharapkan. Oleh sebab itu penyelenggara pelayanan disarankan secara berkala wajib melakukan Survei Indeks Kepuasan Masyarakat untuk mengetahui kinerja pelayanannya, misalnya kepuasan terhadap pelayanan Surat Laik Operasi (SLO) Kapal Perikanan dan Surat Aktifasi Transmitter (SKAT) yang diselenggarakan Ditjen Pengawasan Sumber Daya Kelautan dan Perikanan (Holle, 2011).

Solusi dalam memperbaiki pelayanan publik kepada masyarakat, pemerintah harus segera bisa mengubah paradigma para aparatur dari mau dilayani menjadi pelayan, karena fungsi utama dari pemerintahan adalah memberikan pelayanan. Fungsi pelayanan inilah yang sering dilupakan oleh para birokrat. 
Hal-hal yang harus dilakukan untuk memperbaiki pelayanan public, diantaranya: 1). Memperbaiki sistem rekruitmen: Sistem rekruitmen sangat penting karena inilah awal dari adanya aparatur pemerintahan. Seleksi aparatur pemerintahan harus diperketat dan tesnya harus diperbaiki, sehingga mampu menghasilkan pegawai yang professional (Aprilia, Wijaya, \& Suryadi, 2014). 2). Memberikan sanksi yang tegas: Dalam proses pelayanan sering kali petugas tidak melakukan apa yang sudah diatur dalam aturan, sehingga masyarakat tidak mendapatkan kepuasan. Petugas yang sering melanggar harus diberikan sanksi yang tegas, kalau perlu dipecat. Dengan adanya sanksi yang tegas diharapkan para aparatur pemerintahan tidak berani melakukan tindakan yang malnggar aturan. 3). Mempermudah proses: Proses yang bisa dikatakan berbelit-belit sering mengandung untuk terjadinya pungli. Jadi lakukanlah dengan tangung jawab terhadap masyarkaat.

\section{Simpulan}

Pelayanan publik atau pelayanan umum dapat didefinisikan sebagai segala bentuk jasa pelayanan, baik dalam bentuk barang maupun jasa yang pada prinsipnya menjadi tanggung jawab dan dilaksanakan oleh Instansi Pemerintah di Pusat, di Daerah, dan di lingkungan Badan Usaha Milik Negara atau Badan Usaha Milik Daerah, dalam rangka upaya pemenuhan kebutuhan masyarakat maupun dalam rangka pelaksanaan ketentuan peraturan perundang-undangan. Berdasarkan Undang-Undang Nomor 25 Tahun 2009 tentang Pelayanan Publik, ruang lingkup pelayanan publik terbagi atas dua bagian, yaitu: Pelayanan Barang dan Jasa Publik, Pelayanan Administratif,

Badan Penyelenggara Jaminan Sosial merupakan sebuah badan hukum untuk menyelenggarakan program jaminan sosial untuk menjamin seluruh rakyat agar dapat memenuhi kebutuhan dasar hidup yang layak. BPJS diselenggarakan berdasarkan asas kemanusiaan, manfaat, dan keadilan sosial bagi seluruh rakyat Indonesia dengan tujuan untuk mewujudkan pemenuhan kebutuhan dasar hidup yang layak bagi setiap rakyat Indonesia yang sudah menjadi hak dasar manusia. BPJS memiliki visi dan misi di dalamnya yang harus dilaksanakan, antara lain: Visi BPJS Kesehatan : "Cakupan Semesta 2019” paling lambat 1 Januari 2019, seluruh penduduk Indonesia memiliki jaminan kesehatan nasional untuk memperoleh manfaat pemeliharaan kesehatan dan perlindungan dalam memenuhi kebutuhan dasar kesehatannya yang diselenggarakan oleh BPJS Kesehatan yang handal, unggul dan terpercaya. 


\section{Daftar Pustaka}

Aprilia, S., Wijaya, A., \& Suryadi, S. (2014). Efektivitas Website Sebagai Media EGovernment dalam Meningkatkan Pelayanan Elektronik Pemerintah Daerah (Studi Pada Website Pemerintah Daerah Kabupaten Jombang). Wacana, Jurnal Sosial Dan Humaniora. https://doi.org/10.21776/ub.wacana.2014.017.03.3

Batubara, A. H. (2006). Konsep Good Governance Dalam Konsep Otonomi Daerah. Analisis Administrasi Dan Kebijakan.

BPJS Ketenagakerjaan. (2016). BPJS Ketenagakerjaan. Bpjs Ketenagakerjaan.

Hardiansyah. (2011). Kualitas Pelayanan Publik. KUALITAS PELAYANAN PUBLIK MENUJU GOOD LOCAL GOVERNANCE. https://doi.org/10.1016/j.jhsa.2008.07.013

Hasan, M., Ayuningtyas, D., \& Misnaniarti, M. (2016). Good Corporate Governance Implementation and Performance of Civil Servant. Kesmas: National Public Health Journal. https://doi.org/10.21109/kesmas.v11i1.855

Hayat (Universitas Islam Malang). (2014). Peningkatan Kualitas Sumber Daya Manusia Aparatur Pelayanan Publik dalam Kerangka Undang-Undang Nomor 5 Tahun 2014 tentang Aparatur Sipil Negara. Civil Servive: Jurnal Kebijakan Dan Manajemen PNS.

Holle, E. S. (2011). Pelayanan Publik Melalui Electronic Government Upaya Meminimalisir Praktek Maladministrasi Dalam Meningkatan Public Service Oleh : Erick S. Holle. Sasi.

Janis, N. (2014). BPJS Kesehatan, Supply dan Demand terhadap Layanan Kesehatan.

Kamarni, N. (2011). Analisis Pelayanan Publik Terhadap Masyarakat (Kasus Pelayanan Kesehatan di Kabupaten Agam. Manajemen Dan Kewirausahaan.

Kurniawan, R. C. (2017). INOVASI KUALITAS PELAYANAN PUBLIK PEMERINTAH DAERAH. FIAT https://doi.org/10.25041/fiatjustisia.v10no3.794

Larasati, E. (2010). Konstruksi Pelayanan Publik di Indonesia. Forum. 2010.

Mahsyar, A. (2011). Masalah Pelayanan Publik di Indonesia Dalam Perspektif Administrasi Publik. Otoritas: Jurnal Ilmu Pemerintahan. https://doi.org/10.26618/ojip.v1i2.22

Muhaimin, M. (2018). Penguatan Penyelenggaraan Pelayanan Publik melalui Penyelesaian Sengketa Informasi Publik. Jurnal Ilmiah Kebijakan Hukum. https://doi.org/10.30641/kebijakan.2018.v12.213-226

Muradi, \& Rusli, Z. (2013). AKUNTABILITAS PELAYANAN PUBLIK. Jurnal Administrasi Pembangunan.

Pemerintah Republik Indonesia. (2011). Undang-Undang RI No 24 Tahun 2011. Tentang Badan Penyelenggara Jaminan Sosial. Jakarta. https://doi.org/10.1017/CBO9781107415324.004

Pertiwi, A. (2017). ANALISIS PERBEDAAN KUALITAS PELAYANAN PADA PASIEN BPJS DAN PASIEN UMUM TERHADAP KEPUASAN PASIEN DI RAWAT JALAN RSUD KOTA SURAKARTA. Jurnal Manajemen Dayasaing. https://doi.org/10.23917/dayasaing.v18i2.4508

Pertiwi, M., \& Nurcahyanto, H. (2017). EFEKTIVITAS PROGRAM BPJS KESEHATAN DI KOTA SEMARANG (Studi Kasus pada Pasien Pengguna Jasa BPJS Kesehatan di Puskesmas Srondol). Journal of Public Policy and 
Management Review.

Pratama, M. H. (2015). Strategi Meningkatkan Kualitas Pelayanan Publik (Studi Deskriptif tentang Strategi UPTD Pengujian Kendaraan Bermotor Tandes Kota Surabaya dalam Meningkatkan Kualitas Pelayanan Pengujian Kendaraan Bermotor). Jurnal Kebijakan Dan Manajemen Publik.

Publik, P., \& Indonesia, P. R. (2009). UU Nomor 25 Tahun 2009 Tentang"Pelayanan Publik". UU Nomor 25 Tahun 2009 Tentang"Pelayanan Publik".

Putri, P. M., \& Murdi, P. B. (2019). PELAYANAN KESEHATAN DI ERA JAMINAN KESEHATAN NASIONAL SEBAGAI PROGRAM BADAN PENYELENGGARA JAMINAN SOSIAL KESEHATAN. Jurnal Wacana Hukum. https://doi.org/10.33061/1.jwh.2019.25.1.3046

Rezha, F., Rochmah, S., \& Siswidiyanto. (2009). ANALISIS PENGARUH KUALITAS PELAYANAN PUBLIK TERHADAP KEPUASAN MASYARAKAT (Studi tentang Pelayanan Perekaman Kartu Tanda Penduduk Elektronik (e-KTP) di Kota Depok). Jurnal Administrasi Publik.

Sirajuddin, I. A. (2016). Implementasi Kebijakan Pemerintah Daerah Dalam Pelayanan Publik Dasar Bidang Sosial Di Kota Makassar. Jurnal Ilmiah Ilmu Administrasi Publik. https://doi.org/10.26858/JIAP.V4I1.1817

Aprilia, S., Wijaya, A., \& Suryadi, S. (2014). Efektivitas Website Sebagai Media EGovernment dalam Meningkatkan Pelayanan Elektronik Pemerintah Daerah (Studi Pada Website Pemerintah Daerah Kabupaten Jombang). Wacana, Jurnal Sosial Dan Humaniora. https://doi.org/10.21776/ub.wacana.2014.017.03.3

Batubara, A. H. (2006). Konsep Good Governance Dalam Konsep Otonomi Daerah. Analisis Administrasi Dan Kebijakan.

BPJS Ketenagakerjaan. (2016). BPJS Ketenagakerjaan. Bpjs Ketenagakerjaan.

Hardiansyah. (2011). Kualitas Pelayanan Publik. KUALITAS PELAYANAN PUBLIK MENUJU GOOD LOCAL GOVERNANCE. https://doi.org/10.1016/j.jhsa.2008.07.013

Hasan, M., Ayuningtyas, D., \& Misnaniarti, M. (2016). Good Corporate Governance Implementation and Performance of Civil Servant. Kesmas: National Public Health Journal. https://doi.org/10.21109/kesmas.v11i1.855

Hayat (Universitas Islam Malang). (2014). Peningkatan Kualitas Sumber Daya Manusia Aparatur Pelayanan Publik dalam Kerangka Undang-Undang Nomor 5 Tahun 2014 tentang Aparatur Sipil Negara. Civil Servive: Jurnal Kebijakan Dan Manajemen PNS.

Holle, E. S. (2011). Pelayanan Publik Melalui Electronic Government Upaya Meminimalisir Praktek Maladministrasi Dalam Meningkatan Public Service Oleh : Erick S. Holle. Sasi.

Janis, N. (2014). BPJS Kesehatan, Supply dan Demand terhadap Layanan Kesehatan.

Kamarni, N. (2011). Analisis Pelayanan Publik Terhadap Masyarakat (Kasus Pelayanan Kesehatan di Kabupaten Agam. Manajemen Dan Kewirausahaan.

Kurniawan, R. C. (2017). INOVASI KUALITAS PELAYANAN PUBLIK PEMERINTAH DAERAH. FIAT

https://doi.org/10.25041/fiatjustisia.v10no3.794

Larasati, E. (2010). Konstruksi Pelayanan Publik di Indonesia. Forum. 2010.

Mahsyar, A. (2011). Masalah Pelayanan Publik di Indonesia Dalam Perspektif Administrasi Publik. Otoritas: Jurnal Ilmu Pemerintahan. https://doi.org/10.26618/ojip.v1i2.22

Muhaimin, M. (2018). Penguatan Penyelenggaraan Pelayanan Publik melalui 
Penyelesaian Sengketa Informasi Publik. Jurnal Ilmiah Kebijakan Hukum. https://doi.org/10.30641/kebijakan.2018.v12.213-226

Muradi, \& Rusli, Z. (2013). AKUNTABILITAS PELAYANAN PUBLIK. Jurnal Administrasi Pembangunan.

Pemerintah Republik Indonesia. (2011). Undang-Undang RI No 24 Tahun 2011. Tentang Badan Penyelenggara Jaminan Sosial. Jakarta. https://doi.org/10.1017/CBO9781107415324.004

Pertiwi, A. (2017). ANALISIS PERBEDAAN KUALITAS PELAYANAN PADA PASIEN BPJS DAN PASIEN UMUM TERHADAP KEPUASAN PASIEN DI RAWAT JALAN RSUD KOTA SURAKARTA. Jurnal Manajemen Dayasaing. https://doi.org/10.23917/dayasaing.v18i2.4508

Pertiwi, M., \& Nurcahyanto, H. (2017). EFEKTIVITAS PROGRAM BPJS KESEHATAN DI KOTA SEMARANG (Studi Kasus pada Pasien Pengguna Jasa BPJS Kesehatan di Puskesmas Srondol). Journal of Public Policy and Management Review.

Pratama, M. H. (2015). Strategi Meningkatkan Kualitas Pelayanan Publik (Studi Deskriptif tentang Strategi UPTD Pengujian Kendaraan Bermotor Tandes Kota Surabaya dalam Meningkatkan Kualitas Pelayanan Pengujian Kendaraan Bermotor). Jurnal Kebijakan Dan Manajemen Publik.

Publik, P., \& Indonesia, P. R. (2009). UU Nomor 25 Tahun 2009 Tentang"Pelayanan Publik". UU Nomor 25 Tahun 2009 Tentang"Pelayanan Publik".

Putri, P. M., \& Murdi, P. B. (2019). PELAYANAN KESEHATAN DI ERA JAMINAN KESEHATAN NASIONAL SEBAGAI PROGRAM BADAN PENYELENGGARA JAMINAN SOSIAL KESEHATAN. Jurnal Wacana Hukum. https://doi.org/10.33061/1.jwh.2019.25.1.3046

Rezha, F., Rochmah, S., \& Siswidiyanto. (2009). ANALISIS PENGARUH KUALITAS PELAYANAN PUBLIK TERHADAP KEPUASAN MASYARAKAT (Studi tentang Pelayanan Perekaman Kartu Tanda Penduduk Elektronik (e-KTP) di Kota Depok). Jurnal Administrasi Publik.

Sirajuddin, I. A. (2016). Implementasi Kebijakan Pemerintah Daerah Dalam Pelayanan Publik Dasar Bidang Sosial Di Kota Makassar. Jurnal Ilmiah Ilmu Administrasi Publik. https://doi.org/10.26858/JIAP.V4I1.1817 